\title{
INSULIN CONTENT AND INSULIN RECEPTORS IN THE RAT BRAIN. EFFECT OF FASTING AND STREPTOZOTOCIN TREATMENT
}

\author{
YOSHIKAZU SAKAMOTO, YUTAKA OOMURA*, HITOSHI KITA*, SHIGENOBU \\ SHIBATA*, SUSUMU SUZUKI, TAKESHI KUZUYA and SHO YOSHIDA \\ Division of Endocrinology and Metabolism, Department of Medicine, Jichi Medical School, Minamikawachi- \\ Machi, Kawachi-Gun, Tochigi-Ken 329-04, Japan, and *Department of Physiology, Faculty of Medicine, \\ University of Kyushu, Fukuoka 812, Japan
}

\begin{abstract}
Insulin content in the brain and the specific binding of ${ }^{125}$ I-insulin to the brain plasma membrane were studied in control, fasted and streptozotocin-treated rats. Insulin content in acid-ethanol extracts of the whole rat brain was always higher than plasma insulin levels. In gel filtration, the brain 'insulin' had the same molecular weight as the standard insulin. The brain insulin content was not changed by fasting or streptozotocin treatment, but was extremely variable among individual animals. The specific binding sites for ${ }^{125} \mathrm{I}$-insulin in the brain were most abundant in the olfactory bulb and hypothalamus, followed by the cerebral cortex, and were least in the cerebellum and pons. The ventromedial hypothalamus (VMH) and the lateral hypothalamus (LHA) contained abundant insulin binding sites. The amount of insulin binding by each part of the rat brain was unaltered by fasting or streptozotocin treatment. The physiological significance of the presence of insulin and insulin receptors in the brain remains obscure.
\end{abstract}

KEY WORDS brain insulin / brain insulin receptor / ventromedial hypothalamus / lateral hypothalamus / fasting / streptozotocin

The brain has been generally considered to be independent of insulin action. Recent reports, however, suggest that insulin may have some physiological role in influencing the brain functions, particularly those concerned with energy metabolism. Administration of insulin into the carotid artery or into the cerebrospinal fluid decreased the peripheral blood glucose concentration, possibly via the vagus nerve and/or via stimulation of insulin secretion $(12,14)$. Insulin is also reported to enhance goldthioglucose binding to neurons in the ventromedial hypothalamic nucleus (VMH) of mice, indicating that the binding of the glucose molecules to the glucoreceptor neuron in the VMH was perhaps facilitated by insulin $(3,4)$. Single unit discharges in the rat olfactory bulb and the amygdala responding to odour stimulation changed in frequency after subcutaneous insulin injection (2). The result has been interpreted to show a close interaction between hunger and olfactory mechanisms (2). Oomura demonstrated that the activity of some neurons in the rat VMH increased after electroosmotic application of glucose in a dose-dependent manner (11). These neurons have been designated as the glucoreceptor neurons. The electro-osmotic application of insulin enhanced the effects of glucose in the glucoreceptor neurons when both glucose and insulin were applied simultaneously, although insulin application alone tended to inhibit the activity (11). In the lateral hypothalamic area (LHA), only glucose-sensitive neurons, whose activity was inhibited by glucose application, were excited by 
insulin in a dose-dependent manner. This excitation indicated a reaction for one molecule per receptor site. The threshold level for insulin effect was approximately $5 \times 10^{-9}$ units (12). This evidence clearly indicates a direct action of insulin on the hypothalamic neurons, existence of insulin receptor sites on the glucose-sensitive neurons in the LHA, and thus a direct involvement of insulin in the neural control of food intake.

Havrankova et al. (7) recently found that there are insulin binding sites in many parts of the rat brain, being most abundantly present in the olfactory bulb. Furthermore, they suggested the possibility of intracerebral biosynthesis of insulin. They also demonstrated that the brain insulin binding sites are independent of peripheral blood insulin concentration, since streptozotocin treatment and genetic obesity did not affect the level of brain insulin and binding capacity (6).

Our studies generally confirm the results of Havrankova et al. and further show that the LHA and VMH have dense insulin binding sites. The effects of fasting and streptozotocin treatment on insulin binding sites and brain insulin content have also been studied.

\section{MATERIALS AND METHODS}

\section{Chemicals}

Monocomponent porcine insulin was obtained from Novo Laboratory (Copenhagen). Streptozotocin and tovine plasma albumin (Fraction V) from Sigma (St. Louis, Mo.), and monoiodinated porcine insulin (NEX 104, $87 \mu \mathrm{Ci} / \mu \mathrm{g}$ ) from New England Nuclear Corp. (Boston).

\section{Animals}

Male Wistar rats (approximately $200 \mathrm{~g}$ ) were used throughout this study. The animals were divided into three groups. Group 1 consisted of diabetic rats, prepared by intraperitoneal injection of streptozotocin $(60 \mathrm{mg} / \mathrm{kg}$, Lot No. $79 \mathrm{c}-0027)$ given 5 days prior to the experiment. Streptozotocin was injected in a volume of $0.5 \mathrm{ml}$ of $0.1 \mathrm{M}$ citrate buffer ( $\mathrm{pH} 4.5$ ). Group 2 consisted of fasting rats, food-deprived for $48 \mathrm{hr}$. Group 3 consisted of control rats, injected with acidified saline 5 days prior to the experiment. Rats in groups 1 and 3 were allowed free access to standard rat chow.

\section{Brain Sampling}

Animals were killed by decapitation and blood was collected into heparinized tubes. Plasma samples for measurement of glucose and immunoreactive insulin concentration were stored at $-20^{\circ} \mathrm{C}$. The brains were dissected macroscopically and divided into 6 parts: olfactory bulb, hypothalamus, cerebral cortex, cerebellum, pons, and others. In some instances VMH and LHA were collected from the hypothalamus and the remaining parts of the hypothalamus were mixed with others. The parts were immediately frozen on dry ice and stored at $-80^{\circ} \mathrm{C}$. The liver was dissected and stored at $-80^{\circ} \mathrm{C}$.

\section{Extraction of Insulin and Gel Filtration}

The whole brain was immediately weighed and ground with a homogenizer (Omega Electric, Type SH-3, Tokyo) at a setting of 3.0 in 10 volumes of ice-cold acid ethanol ( $\mathrm{HCl} 0.2 \mathrm{~N}$, ethanol $75 \%$ ). The suspension was mildly shaken for $24 \mathrm{hr}$ at $4^{\circ} \mathrm{C}$. After centrifugation at $1,500 \mathrm{~g}$ for $20 \mathrm{~min}$ at $4^{\circ} \mathrm{C}$, the supernatant was concentrated by air evaporation at $24^{\circ} \mathrm{C}$ to about $1 / 20$ th of the original volume. The concentrate was suspended in about 5 volumes of $\left(\mathrm{NH}_{4}\right)_{2} \mathrm{CO}_{3}(0.05 \mathrm{M})$ containing $1 \mathrm{mg} / \mathrm{ml}$ bovine serum albumin and was neutralized with $\mathrm{NH}_{4} \mathrm{OH}$. Samples were centrifuged at $1,500 \mathrm{~g}$ for $20 \mathrm{~min}$ at $4^{\circ} \mathrm{C}$. The supernatant was lyophilized. It was dissolved in borate buffer (pH 8.6) for radioimmunoassay (8). The recovery of the extraction procedures was estimated by the method of Havrankova et al. (7). A tracer amount of ${ }^{125}$ I-insulin was added before the extraction and the remaining radioactivity was counted after the extraction procedure, and the recovery was expressed as percentage of the initial counts. Estimated recovery was between 42 and $52 \%$. The values for insulin content were all corrected by the recovery. A lyophilized extract of streptozotocin-treated rat brain was dissolved in $1 \mathrm{ml}$ of $0.05 \mathrm{M}\left(\mathrm{NH}_{4}\right)_{2} \mathrm{CO}_{3}$ containing bovine albumin, applied to a Sephadex G-50 fine column $(0.9 \times 58 \mathrm{~cm})$, and eluted with $0.05 \mathrm{M} \quad\left(\mathrm{NH}_{4}\right)_{2} \mathrm{CO}_{3}$ solution. One $\mathrm{ml}$ fractions were collected and the insulin concentration in each fraction was determined by radioimmunoassay. The column was calibrated with ${ }^{125} \mathrm{I}$-insulin and blue dextran.

\section{Assay of Insulin Receptors}

The crude plasma membrane fraction was prepared from tissues according to the method of Tsushima and Friesen (15). The brain and the liver were homogenized in 5 volumes of ice-cold 
$0.3 \mathrm{M}$ sucrose with a homogenizer for $60 \mathrm{sec}$ and centrifuged for $20 \mathrm{~min}$ at $10,000 \mathrm{~g}$ at $4^{\circ} \mathrm{C}$. The supernatants were recentrifuged under the same conditions. The supernatants were then centrifuged at $100,000 \mathrm{~g}$ for $90 \mathrm{~min}$ at $4^{\circ} \mathrm{C}$. The $100,000 \mathrm{~g}$ pellet was suspended in $25 \mathrm{mM}$ Tris-HC1 buffer ( $\mathrm{pH} 7.6$ ) and stored at $-80^{\circ} \mathrm{C}$. The assay was carried out in borosilicate tubes $(12 \times 75 \mathrm{~mm})$ containing 200 $\mu \mathrm{l}$ of $0.1 \mathrm{M}$ Tris-HC1 buffer $(0.1 \% \mathrm{BSA}, 10 \mathrm{mM}$ $\mathrm{CaCl}_{2}, 2 \mathrm{mM}$ N-ethylmaleimide, $\mathrm{pH} 7.6$ ), $50 \mu \mathrm{l}$ of the $100,000 \mathrm{~g}$ pellet (approximately $150 \mu \mathrm{g}$ of protein), $50 \mu l$ of ${ }^{125} \mathrm{I}$-insulin (about $50,000 \mathrm{cpm}$ ), and $100 \mu l$ of the buffer or various concentrations of standard monocomponent pork insulin. The tubes were chilled in a melting ice bath throughout the assay procedure and overnight incubation was performed at $4^{\circ} \mathrm{C}$. Samples were then centrifuged at $3,000 \mathrm{~g}$ for $30 \mathrm{~min}$, the supernatant was decanted, and the pellet was washed with $1 \mathrm{ml}$ of the buffer and recentrifuged under the same conditions. Radioactivity of the pellet was counted. Radioactivity in the presence of $100 \mu \mathrm{g} / \mathrm{ml}$ of unlabeled insulin was designated as

Table 1 Plasma Glucose and Plasma Insulin Concentrations in Experimental Animals

\begin{tabular}{|c|c|c|c|}
\hline & Control group & Fasting group & Streptozotocin-treated group \\
\hline Number & 30 & 37 & 29 \\
\hline $\begin{array}{l}\text { Plasma glucose } \\
(\mathrm{mg} / 100 \mathrm{ml})\end{array}$ & $133.7 \pm 16.0$ & $88.11 \pm 17.3^{*}$ & $518.7 \pm 140.6^{*}$ \\
\hline $\begin{array}{l}\text { Plasma insulin } \\
(\mu \mathrm{U} / \mathrm{ml})\end{array}$ & $26.6 \pm 11.1$ & $8.4 \pm 4.4 \%$ & $10.1 \pm 7.6^{*}$ \\
\hline
\end{tabular}

Values are expressed as mean \pm S.D. * represents a significant difference $(P<0.001)$ from the control value. Rats in the fasting group were fasted for $48 \mathrm{hr}$. Streptozotocin-treated rats were sacrificed five days after streptozotocin injection $(60 \mathrm{mg} / \mathrm{kg}$, i.p.).

Table 2 Insulin Content in the Brain

\begin{tabular}{|c|c|c|}
\hline Rat No. & $\begin{array}{l}\text { Brain insulin content } \\
(\mu \mathrm{U} / \mathrm{g} \text { w.w. })\end{array}$ & $\begin{array}{c}\text { Plasma insulin level } \\
(\mu \mathrm{U} / \mathrm{ml})\end{array}$ \\
\hline \multicolumn{3}{|l|}{ Control group } \\
\hline 1. & 185.6 & 49.4 \\
\hline 2. & 85.2 & 38.2 \\
\hline 3. & 81.2 & 27.2 \\
\hline 4. & 65.6 & 24.7 \\
\hline 5. & 104.4 & 37.0 \\
\hline 6. & 160.0 & 36.2 \\
\hline \multicolumn{3}{|l|}{ Fasting group } \\
\hline 7. & 59.4 & 4.6 \\
\hline 8. & 654.0 & 12.5 \\
\hline 9. & 63.4 & 9.5 \\
\hline 10. & 53.2 & 5.2 \\
\hline 11. & 69.6 & 7.5 \\
\hline 12 & 175.4 & 5.0 \\
\hline \multicolumn{3}{|c|}{ Streptozotocin-treated group } \\
\hline 13. & 99.0 & 9.5 \\
\hline 14. & 86.2 & 17.0 \\
\hline 15. & 65.6 & 7.8 \\
\hline 16. & 68.8 & 5.3 \\
\hline 17. & 63.0 & 2.8 \\
\hline 18. & 88.8 & 6.2 \\
\hline 19. & 40.0 & 10.0 \\
\hline
\end{tabular}

Rats were injected with streptozotocin, $60 \mathrm{mg} / \mathrm{kg}$, i.p. (streptozotocin-treated group), and were killed five days after the injection. Rats in the fasting group were fasted for $48 \mathrm{hr}$. The brain was extracted with acidethanol and the insulin content determined by radioimmunoassay as described in the text. 
non-specific binding and subtracted from the total binding to obtain the specific binding.

\section{RESULTS}

\section{Plasma Glucose and Insulin Concentrations}

As shown in Table 1, streptozotocin-treated rats became diabetic. Plasma glucose levels increased to about 3.9 times the control value, while plasma insulin levels decreased to $38 \%$ of the control value. In the fasting group, both plasma glucose and insulin levels decreased to about $66 \%$ and $30 \%$ of those in the control group, respectively. Plasma glucose and plasma insulin levels of the fasting group and the streptozotocin-treated group were significantly different from the control group. There was no significant difference in insulin concentration, however, between the fasting and the streptozotocin-treated groups.

\section{Insulin Content in the Brain}

Insulin content in the extract of the whole brain and plasma insulin concentration in the 3 groups of rats are summarized in Table 2. The insulin content of the brain was similar in all three groups, but always higher than that of plasma insulin. Plasma insulin concentration was higher in all the control rats than in the fasting and the streptozotocin-treated animals.

Gel filtration of an extract from rat brain revealed a main peak of immunoreactive insulin in the region where ${ }^{125}$ I-insulin is to be eluted (Fig. 1). A small amount of immunoreactivity was detected at the void volume.

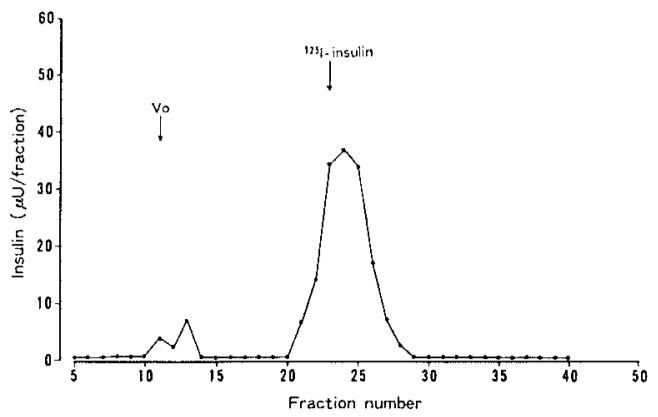

Fig. 1 Gel filtration of the extract of rat brain. Extract corresponding to about $200 \mu \mathrm{U}$ of insulin from the whole brain (streptozotocin-treated rat) was applied to a Sephadex G-50 fine column $(0.9 \times$ $58 \mathrm{~cm})$ and eluted with $0.05 \mathrm{M}\left(\mathrm{NH}_{4}\right)_{2} \mathrm{CO}_{3}$ solution $(1 \mathrm{mg} / \mathrm{ml} \mathrm{BSA})$. The arrows indicate the void volume (Vo) and the peak of ${ }^{125}$ Iinsulin. Each tube contained one $\mathrm{ml}$.

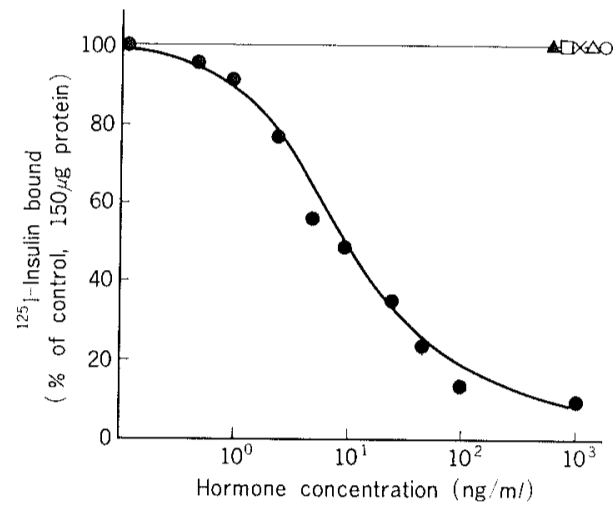

Fig. 2 A typical standard curve of ${ }^{125} \mathrm{I}$-insulin binding to plasma membrane from the whole brain of rats. Preparation of the plasma membrane fraction and the incubation were performed as described in the text. ${ }^{125}$ I-insulin binding is expressed as percentage of maximum control per $150 \mu \mathrm{g}$ of protein/tube. In the presence of insulin ( $)$, glucagon $(O), A C T H$ $(\beta 1-24 ; \triangle)$, human growth hormone $(x)$, triiodothyronine $(\square)$ and vasopressin ( $\Delta$ )

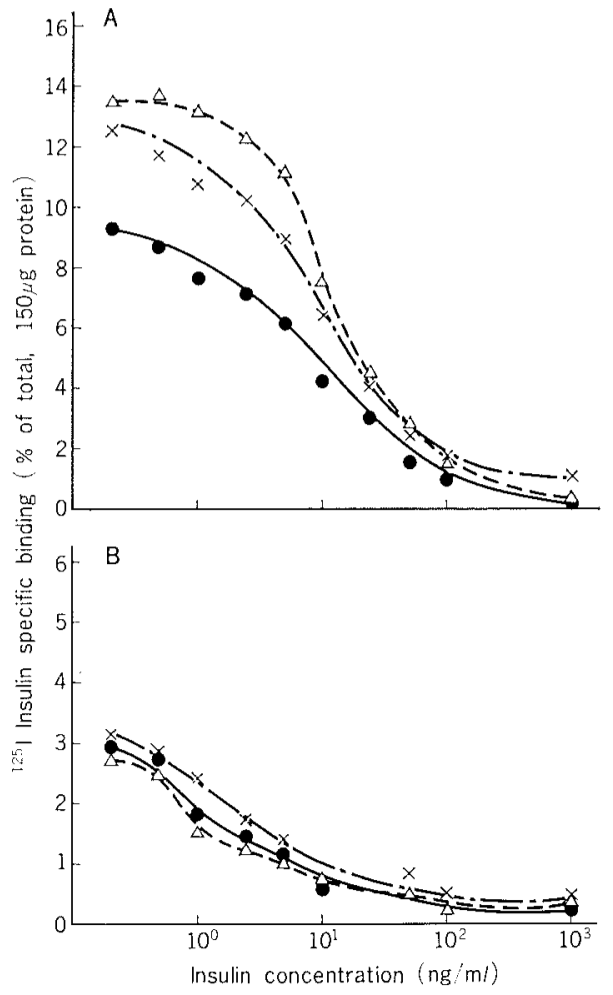

Fig. 3 Specific binding of ${ }^{125}$ I-insulin to the livet membrane (A) and the whole brain membrane (B) prepared from control $(-\bullet)$, fasted $\left(\Delta^{---\hat{\Delta})}\right.$, and streptozotocin-treated $(x \cdot-\cdot x)$ animals. Specific binding of ${ }^{125}$ I-insulin is plotted as a function of concentration of pork insulin. Binding was calculated per $150 \mu \mathrm{g}$ of protein. 
Insulin Binding Sites (Receptors) in the Brain: Distribution and the Effects of Fasting and Streptozotocin-Treatment

Fig. 2 is a typical displacement curve of specific binding of ${ }^{125}$ I-insulin to plasma membrane fraction from whole brain of the control rats. The high concentration of unlabeled insulin $\left(10^{3} \mathrm{ng} / \mathrm{ml}\right)$ reduced the binding of ${ }^{125} \mathrm{I}$-insulin to about $10-15 \%$ of the control value. Half maximal displacement of ${ }^{125}$ I-insulin was observed at the concentration of about $10 \mathrm{ng} / \mathrm{ml}$. Synthetic ACTH (B1-24, Organon), human growth hormone, triiodothyronine, glucagon and vasopressin did not displace ${ }^{125}$ I-insulin binding even at higher concentrations.

Insulin receptors in the liver and the brain were compared in the fasting, the streptozotocintreated and the control groups. As shown in Fig. 3, specific binding of ${ }^{125}$ I-insulin to the liver plasma membrane from the fasted rats or streptozotocin-treated rats was about 1.5 times higher than in the control rats. The concentration of insulin which produced a $50 \%$ decrease in the binding of ${ }^{125} \mathrm{I}$-insulin was about $10 \mathrm{ng} / \mathrm{ml}$, and was not changed between both experimental groups and the control group. Specific binding of ${ }^{125}$ I-insulin to the brain plasma membrane prepared from the fasting and the streptozotocintreated groups was almost the same as in the control group.

The distribution of insulin binding sites in the brain are shown in Fig. 4. The specific binding to the $100,000 \mathrm{~g}$ pellet of each part of the brain is expressed as percentage of the binding by the olfactory bulb in the control animals. The specific binding was the highest in the olfactory bulb and hypothalamus. The amount in the VMH and LHA was virtually the same as those in olfactory bulb and hypothalamus. The lowest contents were found in the cerebellum and pons. Fasting and streptozotocin-treatment did not change the specific binding of ${ }^{125}$ I-insulin to the plasma membrane fractions obtained from the various brain regions such as olfactory bulb, hypothalamus, cerebral cortex, cerebellum, pons and others.

\section{DISCUSSION}

The present experiments confirm the existence of insulin-like peptide (7) and insulin binding sites (6) in the rat brain. Specific binding sites in the brain for ${ }^{125} \mathrm{I}$-insulin were most abundant in the olfactory bulb and hypothalamus, followed by the cerebral cortex, cerebellum and pons in decreasing order. One new finding in this study is that both VMH and LHA contain abundant insulin binding sites. The physiological significance of insulin binding in the brain is still obscure. The presence of specific receptors is a prerequisite for the action of insulin, but does not necessarily imply that the tissue is regulated by this hormone. Erythrocytes and kidney, for example, have insulin binding sites but no clear insulin-dependent metabolic process has ever been found in these tissues.

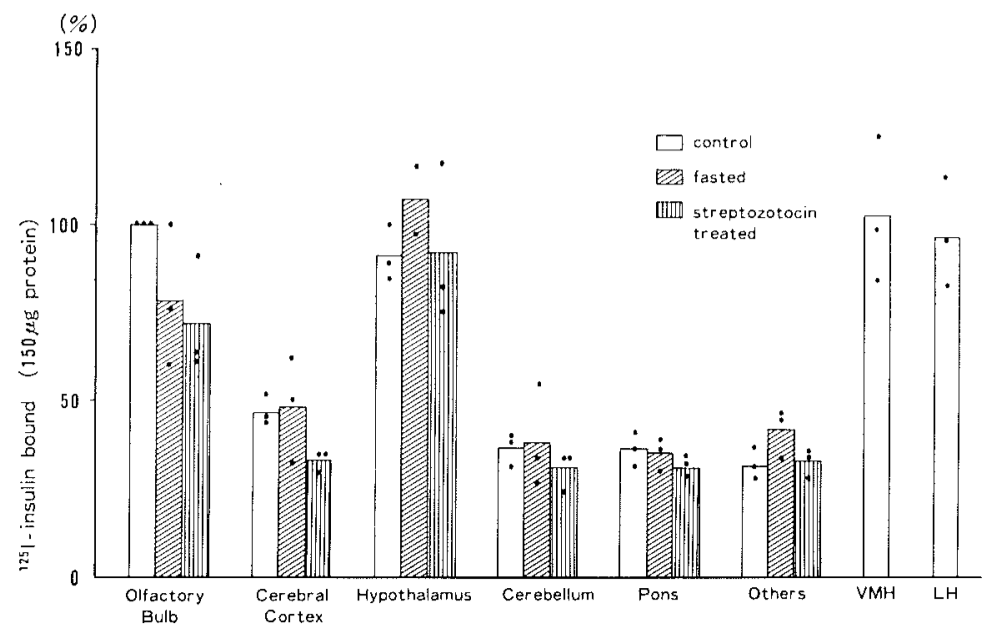

Fig. 4 Distribution of insulin binding to brain plasma membranes in various portions of the brain from control, fasting, and streptozotocin-treated animals. ${ }^{125}$ I-insulin binding was expressed as percentage of specific binding $(100 \%)$ in the olfactory bulb in the control animals. 
It has been questioned whether insulin could reach the brain tissue through the blood-brain barrier. Studies with the use of ${ }^{125}$ I-insulin have suggested that insulin can penetrate into the brain to some extent (5). In some areas of the hypothalamus, the nerve cell membranes are directly attached to capillary walls without the thin astroglia membrane, suggesting the lack of the blood-brain barrier in these areas $(10,11)$. Therefore, it cannot be denied that metabolism in some parts of the hypothalamus is regulated by blood insulin levels, although the brain as a whole may appear to be insulin-independent. It is interesting that insulin binding sites are more abundant in those areas of the brain, such as the VMH, LHA and olfactory bulb, which are related to food intake $(1,9)$. The electrical activities of these areas are known to be affected by glucose and insulin. Electro-osmotic applications of glucose increased the discharge rate of the glucoreceptor neurons in the rat VMH and simultaneous application of glucose and insulin further enhanced the activity. The firing rate of the glucose-response manner and this might indicate the existence of insulin receptors. It is quite likely that these insulin receptors play a physiologically significant role in the regulation of food intake and energy metabolism, responding to the changes in the blood insulin level.

The amount of insulin-binding sites in the various parts of the brain and insulin content in the whole brain did not change either after fasting or in streptozotocin-induced diabetes. This is in good agreement with the results of Havrankova et al. (6).

The brain insulin appears indistinguishable from true insulin in its molecular size and immunoreactivity with guinea pig antiserum. The brain insulin content in the present experiment is much less than that reported by Havrankova et al. (7). Whether the brain insulin is derived from blood insulin or locally synthesized is still unknown, although the persistence of brain 'insulin' in streptozotocin rats favors the latter possibility. If insulin is synthesized in the brain, it may have a different functional role from that in the peripheral circulation: insulin may exert a metabolic regulation of neurons or glial cells or it may act as a neurotransmitter or neuromodulator. If most of the insulin binding sites in the brain have a physiological significance, it needs to be elucidated whether they are for the brain 'insulin' or for circulating insulin. We propose that insulin receptors in the hypothalamus may be responding at least in part to blood insulin.
Received for publication 23 June 1980

\section{REFERENCES}

1. Brobeck J. R., Tepperman J. and Long C. H N. (1943) Experimental hypothalamic hyperphagia in the albino rat. Yale J. Biol. Med. 15, 831-853

2. CAIN D. P. (1975) Effects of insulin injection on responses of olfactory bulb and amygdala single units to odors. Brain Res. 99, 69-83

3. Debons A. F., Krimsky I. and From A. (1970) A direct action of insulin on the hypothalamic satiety center. Am. J. Physiol. 219, 938-943

4. Debons A. F., Krimsky I., From A. and Cloutier R. J. (1969) Rapid effects of insulin on the hypothalamic satiety center. Am. J. Plysiol. 217, 1114-1118

5. Goodner C. J. and Berrie M. A. (1977) The failure of rat hypothalamic tissues to take up labeled insulin in vivo or to respond to insulin in vitro. Endocrinology 101, 605-612

6. Havrankova J., Roth J, and Brownstein M. J. (1979) Concentrations of insulin and of insulin receptors in the brain are independent of peripheral insulin levels. $J$. Clin. Invest. 64 , 636-642

7. Havrankova J., Schmechel D., Roth J. and BROWNSTEIN M. (1978) Identification of insulin in rat brain. Proc. Natl. Acad. Sci. USA 75 5737-5741

8. Mirsky I. A. (1973) Insulin; purification and biochemical characterization. In Methods in Investigative and Diagnostic Endocrinology (ed. Berson S. A.) American Elsevier Publishing Co., Inc., New York. 2B, pp. 823-883

9. MAYER J. (1960) The hypothalamic control of gastric hunger contractions as a component of the mechanism of regulation food intake. $A m$. J. Clin. Nutr. 8, 547-561

10. Oldendorf W. H. (1975) Permeability of the blood-brain barrier. In The Nervous System, Vol. 1. The Basic Neurosciences (ed. TowER D. B.) Raven Press, New York, pp. 279-289

11. Oomura Y. (1973) Central mechanism of feeding. In Advances in Biophysics, Vol. 5 (ed. Kotani M.) Tokyo University Press, Tokyo, pp. $65-142$

12. Oomura Y., Sugimori M., Nakamura T. and YamadA Y. (1975) Contribution of electrophysiological techniques to the understanding of central control systems. In Neural Integration of Physiological Mechanisms and Behavior (ed. Mogenson J. and Calaresn F. R.) Toronto University Press, Toronto, pp. 375-395

13. OOMura Y. (1976) Significance of glucose, insulin and free fatty acid on the hypothalamic feeding and satiety neurons. In Huther; Basic Mechanism and Clinical Implications (ed. Novin D., Wyrwicka W. and Bray G.) Raven Press, New York, pp. 145-157 
14. Szabo O. and Szabo A. J. (1975) Studies on the nature and mode of action of the insulin-sensitive glucoregulator receptor in the central nervous system. Diabetes 24, 328-336

15. Tsushima T. and Friesen H. G. (1973) Radio- receptor assay for growth hormone. J. Clin. Endocrinol. Metab. 37, 334-337

16. Woods S. C. and Porte D. (1975) Effect of intracisternal insulin on plasma glucose and insulin in the dogs. Diabetes 24, 905-909 